\title{
Feminist Perspectives in Health Law
}

\author{
Seema Mohapatra and Lindsay F. Wiley
}

$\mathrm{M}$ ounting evidence from the field of social epidemiology ${ }^{1}$ demonstrates that social factors play a crucial role in determining health outcomes. ${ }^{2}$ Law itself is a social determinant of health, structuring the relationships between health outcomes and poverty, racism, educational attainment, ableism, employment status, housing status, involvement in the criminal justice system, the built environment, the economic environment, the information environment, nationalism, homophobia, transphobia, misogyny, and more. ${ }^{3}$ As Scott Burris has written, "[r]esponding to the findings of ... social epidemiology is perhaps the true 'grand challenge' of our time in public health." Some fret that reconceptualizing poverty, racism, and other social ills as health threats will privilege government intervention at the expense of liberty. ${ }^{5}$ Others worry that embracing the expansive relationship between law and health threatens the coherence of health law as a distinct field of academic inquiry and offers few benefits in return. ${ }^{6}$ These criticisms beg the question: What does health law scholarship gain from viewing health as contingent on social structures?

As feminists, we embrace the vast terrain that social epidemiology opens up for exploration by health law scholars. We view health law as an inherently dynamic and expansive field. ${ }^{7}$ What health law scholarship gains from the insights of social epidemiology is an invitation to engage with the rich literature of critical legal theories that view law as an expression of social power. ${ }^{8}$ Rather than claiming poverty law, disability law, edu-

Seema Mohapatra, J.D., M.P.H., is an Associate Professor of Law and Dean's Fellow at Indiana University Robert $H$. McKinney School of Law. Lindsay F. Wiley, J.D., M.P.H., is a Professor of Law and Director of the Health Law and Policy Program at American University Washington College of Law. cation law, housing law, employment law, criminal law, or any other field as health law, social epidemiology invites health law scholars to join ongoing efforts to examine how these diverse areas of law are intertwined with health law, how they support existing social injustices, and how they reflect biases against the very people they purport to serve. This engagement, we argue, has enormous potential to enrich health law scholarship and teaching - on issues that relate to gender specifically, as well as other areas of inequality more broadly.

In this essay, we put forward one group of critical perspectives, under the umbrella of feminist legal theory, as offering crucial but underutilized lenses for assessing and enriching health law and policy. By asking "the woman ${ }^{9}$ question,"10 feminist legal theorists "proffer[] explanations of law's complicity in the ongoing subordination of women and sexual minorities, while also pursuing the possibilities within law for achieving lasting gender and sex equality." ${ }^{11}$ By probing the ways in which "the modern legal subject has retained certain secondary characteristics that continue to cent[er] on the needs and political sensibilities of an eighteenth-century male citizen sheltered by institutions such as the patriarchal family and the privileges of a master-servant mentality," ${ }^{2}$ feminist frameworks help unpack how a male-centered view of law's role in our social world is harmful. ${ }^{13}$ Examples of how health laws and policies have reflected and reinforced white male patriarchy abound, including how the law fails to protect reproductive health decisions and instead treats it as an exception to accepted principles of bodily and decisional autonomy, restrictions on the practice of midwifery and nursing that privileged the professionalization of medical practice, and the notion that public measures to support access 
to health care and healthy living conditions must be justified by exceptional circumstances against a background norm of personal responsibility.

We do not attempt to describe every theoretical framework within feminist legal theory that may be helpful to health law scholars and teachers. Instead, we draw on specific (and interrelated) theoretical frameworks developed by feminist legal theorists, including relational autonomy, intersectionality, feminist critiques of the public-private divide, and vulnerability theory. The feminist theory of relational autonomy, championed by Jennifer Nedelsky and others, situates the legal subject within the context of social relationships, allowing "both law and rights [to] be understood in terms of the relations they structure - and how those relations can structure core values, such as autonomy." ${ }^{14}$ Feminists emphasizing the intersectionality of race and gender, in an approach pioneered by Kimberlé Crenshaw, ${ }^{15}$ highlight the limits of rights- and choice-based feminism and broaden the scope of feminist legal inquiry in health law and policy beyond the issue of reproductive rights. ${ }^{16}$ Feminist legal theorists' foundational critique of the publicprivate divide in law reveals how shielding the private sphere from government intervention and support reinforces patriarchal notions of individual liberty (for some) and private responsibility (often unfulfilled or unfulfillable) that limit government interventions to promote health and wellbeing. ${ }^{17}$ Vulnerability theory, pioneered by Martha Albertson Fineman, challenges the privatization ${ }^{18}$ and stigmatization of dependency by emphasizing that all people are inherently vulnerable and dependent on social support to build resilience, which a responsive state is obligated to provide. ${ }^{19}$

We argue that these frameworks provide insights relevant not only to issues that obviously relate to gender (such as those associated with reproductive and sexual health or sex-based discrimination by health care providers, private insurance companies, or public health programs), but also to matters of health care choice, quality, and access ${ }^{20}$ and public health, that are less obviously gender-related..$^{21}$ Feminist perspectives are particularly apt at a time when judges are being called on to craft resolutions to disputes over sex and gender that will reverberate for generations. ${ }^{22}$ Feminist perspectives on the most pressing issues in health law and policy also promise to enrich student learning and further the development of health law scholarship as a field. This essay maps three key areas of existing scholarship and future inquiry at the intersection of health law and feminist legal theory: (I) patient choice and relational autonomy, (II) patriarchy, power, and patient safety, and (III) access to health care and healthy living conditions at the pub- lic-private divide. In each of these areas, we highlight examples of scholarship using feminist legal theory frameworks to advance health justice and also suggest additional challenges in health law teaching and scholarship that would benefit from such analysis.

\section{Patient Choice and Relational Autonomy}

Matters of choice and autonomy are hotly contested within feminist legal theory. Women's reproductive freedom was a dominant focus of feminist movements and classically liberal feminist legal theory in the mid-twentieth century. Recent developments, such as abortion informed consent laws, ${ }^{23}$ and concerns about obstetric violence, ${ }^{24}$ are sparking health law scholarship at the intersection of reproductive justice and health justice, breaking down the silos that have traditionally separated reproductive health from health law and policy writ large. ${ }^{25}$ These developments create new opportunities to enrich health law and policy scholarship by applying feminist perspectives. Feminist theories, including the concepts of relational autonomy and intersectionality, can help inform priorities, values, limitations, and solutions to various aspects of health care decision-making, including with respect to matters unrelated to reproduction.

\section{Reproductive Health Care Decisions}

In the late-twentieth century, reproductive justice advocates adopted an intersectional perspective to broaden their focus beyond the right to choose abortion. Loretta Ross, one of the founders of the reproductive justice movement, purposefully avoided the term "pro-choice" because she noted that Black women often face few real choices. ${ }^{26}$ Engaging with a reproductive justice frame allows a rich discussion of the unique problems that Black women face in raising children and accessing health care, including abortion and proper maternity and post-maternity care, an issue we will turn to below. But even as that focus has expanded to encompass the broader context in which women make decisions about whether to have children and how to parent the children they have, the authors of foundational works on reproductive rights and reproductive justice have only engaged health law and policy frameworks to a limited extent.

The feminist theory of relational autonomy is particularly relevant, but undertheorized, in health care law. The concept of relational autonomy focuses on the context in which people make decisions. ${ }^{27} \mathrm{~A}$ relational self emerges from and is continuously shaped by the context of multiple relationships with other individuals and institutions - some of which can promote flourishing and some of which can oppress. ${ }^{28}$ Relational autonomy acknowledges that autonomy is 
not a black and white concept where you either are autonomous or you are not. It views the individual as embedded within a complex set of relationships. ${ }^{29}$

Relational autonomy allows us to look beyond formal informed consent and acknowledge the reality that each individual choice - about reproductive health care, health care more generally, and other matters related to health - occurs within a complex web of personal and societal relationships, pressures, and obligations. ${ }^{30}$ In the health care arena, this includes examining the constraints and influences a patient faces when making any health care decision. Just because a person consents to a procedure or course of action does not necessarily mean that such consent is a result of an autonomous decision. For example, Pamela Laufer-Ukeles has critiqued the narrowness of the informed consent doctrine in the context of reproductive choices, noting that it ignores the political and public context of abortion and other reproductive decision-making. ${ }^{31}$ She suggests that "relational revising, pursuing one's interests and goals that is exercised, protected, and corroded within relationships and social structures which together shape the individual and determine others' responses to her." ${ }^{38}$ Health law scholarship considering any form of healthcare decision-making could benefit from engaging with Downie and Llewellyn's theoretical vision of autonomy. Recently, for example, Megan Wright has noted that "structural changes to ... the provision and financing of long-term care ... could decrease the burden on families, which may change how people make decisions at the end of life. The background conditions of social and economic inequality decrease true autonomy." 39

One area particularly ripe for further consideration from a relational autonomy perspective is patient compliance with medical advice, particularly at a time when health care providers are increasingly subject to financial incentives that hold them responsible for patient outcomes. ${ }^{40} \mathrm{~A}$ wide variety of factors, such as

\section{Relational autonomy - and feminist legal theory more broadly - have obvious relevance to matters of reproductive choice. But they could also be applied to health care decisions that range far beyond reproduction. The concept of relational autonomy has been applied in the context of reproductive choices, and reproductive technologies, as well as to allocation of health care resources, and end-of-life decisions. It has the potential to be applied in other contexts as well.}

autonomy ... be used to transform the informed consent process into a more balanced and comprehensive consultation that better supports women's autonomy in the context of reproductive choices." 32

\section{Health Care Decisions beyond Reproductive Health}

Relational autonomy - and feminist legal theory more broadly - have obvious relevance to matters of reproductive choice. But they could also be applied to health care decisions that range far beyond reproduction. The concept of relational autonomy has been applied in the context of reproductive choices, ${ }^{33}$ and reproductive technologies, ${ }^{34}$ as well as to allocation of health care resources, ${ }^{35}$ and end-of-life decisions. ${ }^{36}$ It has the potential to be applied in other contexts as well.

Jocelyn Downie and Jennifer Llewellyn describe relational theory "to be a theoretical framework with extraordinary potential for health law and policy." ${ }^{37}$ Downie and Llewellyn define autonomy under a relational lens as "the capacity for defining, questioning, lack of familial support, financial insecurity, housing insecurity, experiences with racism, misogyny, homophobia and other forms of psychosocial stress, can affect whether and how a patient can adhere to a prescribed course of treatment. People make individual health care decisions based upon where they are situated. Considering the relational context in which health care decision-making is occurring is important to consider, especially when theorizing the role of law in such decisions and teaching students about patient choice and patient responsibility.

\section{Patriarchy, Power, and Patient Safety}

Most health law courses address the role of law as a tool for promoting health care quality and patient safety. Medical errors are a serious health care issue, killing more people yearly in the United States than car accidents, AIDS, or breast cancer. ${ }^{41}$ Efforts to tackle medical errors and other problems with quality of care have generated substantial health law schol- 
arship. However, the hierarchical and gendered relationship between nursing and medicine and between the doctor and patient, demonstrated throughout health care case law, and how this affects patient care and patient dignity, remains underexplored. These issues may receive more sustained attention from health law scholars in response to research revealing that African-American, Native American and Alaska Native women are three times more likely to die from pregnancy related causes, compared to white women in the United States. ${ }^{42}$ These startling disparities, which have captured national media attention, are ripe for an intersectional health law analysis focusing on reproductive justice, health justice, gender, and racial justice.

\section{Gender Dynamics in the Health Care Workforce}

Studies show that nurses and allied health professionals often do not communicate their opinions to physicians, even when it could prevent mistakes and improve the patient experience in clinical care. ${ }^{43}$ Medical sociologists focusing on these dynamics have generated a rich body of literature, ripe for incorporation into health law teaching and scholarship. As Lisa Ikemoto has noted, adopting an intersectional lens, "the health system, and the medical hierarchy within it, replicate many of society's power relationships: between doctors and nurses, doctors and clients and nurses and clients." ${ }^{44}$ Not surprisingly, power imbalances between physicians, nurses, and allied health workers have been demonstrated to result in poorer health outcomes for patients. ${ }^{45}$

A collaborative model, rather than a hierarchical model, may improve clinical care quality. ${ }^{46}$ Examining the racial and gender dynamics of the health care workforce with an intersectional lens are valuable additions to the health law literature, given the racial and gender composition of hospital staff. ${ }^{47}$ Sociologist Evelyn Nakano Glenn has studied the hierarchical race and gender division of labor at hospitals: "at the top are the physicians, setting policy and initiating work for others; they are disproportionately white and male. Directly below, performing medical tasks and patient care as delegated by physicians and enforcing hospital rules, are the registered nurses ..., who are overwhelmingly female and disproportionately white. Under the registered nurses and often supervised by them are the licensed practical nurses ..., also female but disproportionately women of color." 48 Jasmine Harris, for example, has developed similar insights in the health law sphere, exploring how the ACA's provisions promoting access to care may deconstruct "traditional hierarchies and power allocation within the medical profession itself (most notably between doc- tors and nurses) as well as between formal health care workers, natural healers, and community supports." 49 The provisions of the ACA promoting integrated care delivery models also lend themselves to examination from an intersectional feminist perspective.

Another quality of care workforce issue that could benefit from feminist legal theorizing are the significant gender imbalances in certain specialties within medicine. Women who are physicians have been found to adopt "the caring" stereotype, which may actually enhance patient care. However, due to gender imbalances in training and gender stereotypes, women physicians choose surgical fields at much lower rates than male physicians. \#ILookLikeASurgeon, a viral online campaign with over a billion impressions, was a social media effort to normalize and celebrate women surgeons. ${ }^{50}$ The lack of women in certain medical specialties is both a quality of care and access to care issue. As to access, if a patient would prefer to have a female surgeon operate on her, that may not be an option due to the lack of women in certain surgical fields. ${ }^{51}$ In terms of quality, some studies have shown that there may be better clinical outcomes with a female doctor, especially for female patients. ${ }^{52}$ There could be myriad reasons for these studies' outcomes, beyond skill of female physicians, and they are worth unpacking with a critical feminist lens.

\section{Gender Dynamics in the Doctor-Patient Encounter}

Some health law scholars have used the work of social scientists to analyze the impact of gender dynamics within medicine on quality health care. For example, Ikemoto has utilized Sue Fisher's fieldwork in women's health clinics to demonstrate the power imbalances that can exist in a patient encounter, especially "where the doctor is typically male, the patients are female and often racial minorities, and the doctor has both the formal education to claim expertise and more formal education than the typical patient." ${ }^{53}$ Ikemoto demonstrates how such doctor-patient encounters can interfere with the communication necessary for safe and appropriate medical treatment.

The sociological literature also discusses gendered relationships between physicians and patients. Health law scholars interested in quality of care may find such literature beneficial in their work. Many sociological studies show that both patients ${ }^{54}$ and nurses ${ }^{55}$ undermine female physicians' authority and legitimacy. Additionally, other studies show that physicians often treat patients differently based on their gender or race. ${ }^{56}$ In health law classes, teachers may find a discussion of gender dynamics, power relationships, and stereotyping would add to students' understanding of health care quality and malpractice liability. 
For example, an intersectional feminist analysis of disparities in maternal mortality would consider the power dynamics at play when an African-American woman seeks prenatal care. Are African-American care providers available to her, which has been associated with better outcomes? Is the woman facing different treatment due to her race in the obstetrician's office or not being offered the same services? This is a multi-faceted issue, but one proposed intervention has been to have midwives, rather than physicians, attend to births. ${ }^{57}$ The racial makeup of midwives is much more diverse than that of obstetricians, which may make a difference in provider-patient trust and communication. ${ }^{58}$ Midwives, who are mostly female, and physicians, who have historically been mostly male, have a long history of conflict and turf wars..$^{59}$ Similar dynamics may also be at work with respect to other health care disparities. For example, women who experience heart attacks are less likely to survive than their male counterparts, but their survival rates are higher when they are cared for by female physicians. ${ }^{60}$ Examining how race and gender shape these power dynamics would lead to a richer understanding and perhaps different, more effective solutions targeting barriers to diversity among health care providers. Many legal frames exist for analyzing and responding to these disparities, but we are suggesting that feminist legal theories offer an important addition to the health law toolbox.

\section{Access to Health Care and Healthy Living Conditions at the Public-Private Divide}

What counts as a health problem, and which of these problems are public, rather than merely personal? Which people and which conditions trigger collective health care financing? Which health threats warrant government efforts to secure healthy living conditions for all members of our society? These questions at the heart of health law and policy seek to demarcate a border between the public and the private. The contested public-private divide is also a crucial focus of feminist scholarship and pedagogy. ${ }^{61}$ According to a common feminist critique, "'public and private' is the source of women's oppression ... because the private realm is exempt from liberal principles and political accountability." 62 Informed by women's lived experience, feminism has embraced the notion that "the personal is political." 63 Some feminist legal theorists, notably Martha Albertson Fineman, have gone further, arguing that the default norm of personal responsibility and the inaccurate assumption that the universal legal subject is autonomous and independent have eroded the ability of our communities to provide the resources needed for human flourishing. ${ }^{64}$

\section{Access to Health Care}

The divide between personal responsibility and public responsibility for securing access to health care is ripe for analysis from feminist perspectives. Although health care has traditionally been dominated by private, common law doctrines privileging health care providers' and insurers' freedom of contract, it is now heavily regulated in ways that purport to secure public values, including equality, dignity, and distributive justice. The Affordable Care Act, in particular, has nudged health care financing and delivery away from an individualistic actuarial fairness model (in which each person is responsible for her own care and that of her family) toward a mutual aid model that embraces social solidarity (in which at least some basic level of care for at least some people is financed collectively through publicly financed programs and mandated risk pooling in the private market). ${ }^{65}$ Expanded health care civil rights protections, requirements that insurers must take all comers, and restrictions on their ability to charge differential rates based on individual risk factors are transforming health care. As Elizabeth McCuskey has described it, there is a "mutuality inherent in public health and the pooling of risk" and thus, it is perhaps unsurprising that the feminist critique of the divide between public and private responsibility for human flourishing has "quietly taken root" in health reform. 66

Feminist legal scholars have long argued that access to health care is a feminist issue and have advocated for universal health care as a necessary condition for economic and racial justice. "Women's daily relationship to securing and maintaining health care for themselves and their children," as Susan Waysdorf has argued, "[is] a major factor in keeping women and their families locked in poverty." 67 The ACA's reforms are consistent with the view that the need for preventive care and medically necessary treatment, regardless of gender, should trigger a mutual aid response; they are matters of public, not merely private, responsibility. ${ }^{68}$ As McCuskey points out, "among the ACA's federal insurance reforms were several provisions that directly address gender disparities: explicit prohibition of sex discrimination by any recipient of federal health care funds (including insurance companies, providers, and assistance programs), prohibition of gender rating[, which has historically produced higher premiums for women], federalizing 'essential health benefits' to include women's preventive care without cost-sharing and maternity and newborn care, and prohibiting pre-existing condition penalties or exclusions, which disproportionately disadvantaged women." 69 Critics of the ACA argue that they "shouldn't have to pay for everyone else's pregnancies,"70 uninten- 
tionally highlighting the implications of the publicprivate divide for women's health care access.

The role of public and private decisionmakers in overseeing access to health care - through the design of benefits packages as well as case-by-case review of claims for coverage or reimbursement - has also garnered attention from feminist legal scholars. They have questioned whether managed care practices, which include utilization review as well as restrictive provider networks and payment structures that incentivize providers to limit patient access to specialty care, might disproportionately harm women..$^{71}$ As Vicki MacDougall put it, "whether managed care has the built in propensity to perpetuate - if not sanction and encourage - medical gender bias to the detriment of the health of women enrolled in managed sal vulnerability undermines the purported divide between public and private responsibility by highlighting the extent to which individuals are universally and inevitably dependent on society and demanding a responsive state to support the resources necessary for resilience..$^{78}$ Drawing on vulnerability analysis, Nicole Huberfeld and Jessica Roberts have argued that "that the preference for private 'hidden' government assistance over public 'visible' government assistance [in health care policy] stems from the American myth of self reliance." 79 Matthew B. Lawrence has built on shared vulnerability analysis and other feminist and communitarian theoretical frameworks to argue that "safety net" programs are in need of a new metaphor that rejects the exceptionalism of a safety net as a last resort and embraces the ecosystem of government

Several health law scholars examining the shifting public-private divide in health care access and financing post-ACA have found Martha Albertson Fineman's vulnerability theory to be a particularly fruitful avenue for integrating feminist perspectives into their analysis of issues ranging from The shared vulnerability frame has been used to analyze a wide variety of health related topics, such as the AIDS epidemic and elder care, to conscience-based restrictions on health care services. Vulnerability theory highlights the inevitable and universal vulnerability and dependency of legal subjects within families, communities, and other social institutions. Universal vulnerability undermines the purported divide between public and private responsibility by highlighting the extent to which individuals are universally and inevitably dependent on society and demanding a responsive state to support the resources necessary for resilience.

care plans"72 is more relevant than ever now as managed care practices continue to evolve and expand beyond private insurance to Medicaid and Medicare.

Several health law scholars examining the shifting public-private divide in health care access and financing post-ACA have found Martha Albertson Fineman's vulnerability theory ${ }^{73}$ to be a particularly fruitful avenue for integrating feminist perspectives into their analysis of issues ranging from The shared vulnerability frame has been used to analyze a wide variety of health related topics, such as the AIDS epidemic $^{74}$ and elder care,,$^{75}$ to conscience-based restrictions on health care services. ${ }^{76}$ Vulnerability theory highlights the inevitable and universal vulnerability and dependency of legal subjects within families, communities, and other social institutions. ${ }^{77}$ Univer- programs and other social structures that determine our access to health care and healthy living conditions. ${ }^{80}$ Vulnerability analysis also casts suspicion on the relegation of care work, including a great deal of health care work, to the private sphere where it is undervalued and disproportionately provided by women on an uncompensated basis. Allison Hoffman has applied these insights to reimagine public and private responsibility for long-term care, which is not covered by private health insurance or Medicare..$^{81} \mathrm{In}$ a work in progress, one of us (Wiley) is exploring the implications of universal vulnerability for proposals to expand access to public health care programs. Additional areas that would lend themselves well to vulnerability analysis include Medicaid work requirements and wellness programs that put the onus on insureds 
and public program enrollees to improve their health outcomes or have their coverage eroded.

The increasingly collective approach to health care financing in the United States begs important questions about which people and which conditions trigger a mutual aid response, questions with crucial implications for women, girls, gender and sexual minorities, and other historically marginalized groups. Legal scholars have paid particular attention to access to health care for women living with HIV/AIDS ${ }^{82}$ as well as women who access health care primarily through systems that segregate them from the mainstream population, such as women who are veterans, ${ }^{83}$ and women who are incarcerated. ${ }^{84}$ Medha Makhlouf has explored the application of the health justice framework, which has feminist roots, to health care access for immigrants, many of whom are excluded from public programs. ${ }^{85}$ With regard to which conditions and which treatments should be collectively financed, the question of whether preventive care is included in the basket of covered services ${ }^{86}$ is of crucial importance to women and girls, who are vulnerable to breast and cervical cancers for which prevention and early detection are essential. Several legal scholars, including one of us (Mohapatra), have examined the role of collective financing, state interests, and feminist engagement in access to reproductive health care for women and girls, which has been exceptionalized by being segregated from and subjected to heightened regulation compared to mainstream health care ${ }^{87} \mathrm{Sta}$ cey Tovino has analyzed the implications of improved scientific understanding of post-partum depression for health law and policy, including interpretation of health insurance policy exclusionary clauses and mental health parity legislation. ${ }^{88}$ Other scholars have questioned the exceptionalism of infertility treatment, which is often excluded from coverage by private insurers and public programs. ${ }^{89}$ The groundbreaking work of these scholars - and many others we do not have sufficient space to mention - draws on feminist perspectives, and there is always more to be done.

\section{Access to Healthy Living Conditions}

In addition to determining "what we owe each other" with regard to medical treatment, the public-private divide - and feminist critiques of it - have implications for "social obligation[s] to protect and promote health" more broadly..$^{90}$ As Norman Daniels has put it, "social justice prevents ill health in more ways than through health care alone." ${ }^{91}$ Thus, feminist commentary on the public-private divide also has implications for laws and policies that determine access to healthy living conditions and other social determinants of good health.
Heart disease, diabetes, and cancer are intuitively framed as "lifestyle" diseases: the result of autonomous choices by individuals, and thus a matter of private concern and personal responsibility. ${ }^{92}$ Other health concerns, such as menstrual hygiene, have been rendered taboo and largely invisible within the public realm..$^{93}$ As the government takes on a greater role in paying for costly medical treatment, the public's interest in preventing disease and injury grows. ${ }^{94}$ At the same time, public health research is revealing the important role played by social, economic, and environmental factors - including racism, ableism, misogyny, homophobia, and transphobia - in constraining individual behavior choices and determining health outcomes. The result is an emerging debate over the legitimate scope of the government's role in ensuring access not just to health care, but to healthy lifestyles and living conditions as well. Increasingly, health threats like diabetes, heart disease, and menstrual hygiene are not simply viewed as personal failures to be addressed through clinical prevention, treatment, and education campaigns. As one of us (Wiley) has argued elsewhere, in the era of new public health, these are increasingly seen as public problems amenable to structural solutions..$^{95}$

While we embrace the potential of new public health law to address racial, economic, and genderbased disparities in health, we do so with a wary eye toward the potential for social biases to shape paternalistic interventions that do more harm than good. Historically, women, girls, and people with minority sexual orientations and gender identities have disproportionately borne the burden of paternalistic policies aimed at securing the public's health and welfare. The supposedly private nature of their choices about sexual practices (about sex work, use of prophylactics, and more) and their parenting choices (about risks during pregnancy, childhood vaccinations, giving children freedom to develop their independence, and more) does not shield them from government intervention intended for their own good (but harmful in practice). ${ }^{96}$ This is true even as the supposedly private nature of the realms (e.g., homes, schools, workplaces, and religious communities) in which they [these marginalized groups] most commonly experience violence, unacceptably unsanitary conditions, and other forms of oppression insulates their oppressors (e.g., parents, intimate partners, superiors, and landlords) from consequences. The work of feminist public health ethicists, such as Wendy Rogers, offers a critical framework for probing the power differentials at play in the processes and substance of public health laws, policies, and governance. ${ }^{97}$ The implications of the public-private divide for access to healthy living 
conditions merits further exploration from feminist health law scholars.

\section{Conclusion}

In each of the three areas we have highlighted in this essay, laws and policies express and reinforce patriarchal and misogynistic ideologies and social structures that oppress women, girls, and people with minority sexual orientations and identities. Uniting these areas of inquiry is a nagging question central to the relationship between critical legal scholarship (including feminist scholarship) and pragmatic action to combat injustice: Can we use legal rights to achieve our aims even as we recognize them as tainted tools that have propped up oppressive social structures? The question has been productively explored by comparative health law scholars, ${ }^{98}$ and it may also be lurking in the background of U.S. health reform (a question ripe for further exploration). As Robert A. Williams, writing about advocacy by indigenous people and other people of color, put it, "rights rhetoric is a primitive weapon, but one we cannot afford to ignore or denigrate, though in our hearts we may question its ultimate utility or relevance once we secure our positions ... [W]e cannot afford the luxury of a wholly negative critique which distances and alienates an already historically proven hostile audience ... We have no choice but to take rights aggressively while we buy the time needed to perfect new weapons out of the materials at hand provided by our insurrectionist discursive traditions." 99 As Robin West has written, "[f]eminist legal theorists both directly and indirectly contribute to the construction of various fields of law - civil rights law, constitutional law, criminal law, tort law, contract law, family law, international law and private law"100 and, as we argue in this essay, health law. "That degree of engagement itself rests on the bedrock assumption that those efforts can at least sometimes bear fruit. Thus, feminist legal theory taken it its entirety has shown, if not consistently expressed, a view of law as not only a mechanism for the subordination of over half the human community but also a potential vehicle for equalizing and improving the quality of life for women and all gender and sexual minorities."101 A feminist agenda for health law and policy must grapple with this dilemma. We hope the result will be a flourishing critical discourse combined with pragmatic calls to deploy laws and policies as weapons to combat gender injustice and health injustice more broadly.

\section{Note}

The authors have nothing to declare.

\section{References}

1. Social epidemiology is "concerned with the way that social structures, institutions, and relationships influence health." L.F. Berkman and I. Kawachi, "A Historical Framework for Social Epidemiology: Social Determinants of Population Health," in L.F. Berkman, I. Kawachi, and M.M. Glymour, eds., Social Epidemiology, 2nd ed. (Oxford: Oxford University Press, 2014): 1-16, at 2.

2. See, e.g., S. Burris, "From Health Care Law to the Social Determinants of Health: A Public Health Law Research Perspective," University of Pennsylvania Law Review 159, no. 6 (2011): 1649-1667, at 1653 ("[C]onsistent correlations across populations between health and various forms of social and economic inequality leave little room for doubt that social arrangements account for an important fraction of population health."); R. Rebouche and S. Burris, "The Social Determinants of Health" in I.G. Cohen, A.K. Hoffman, and W.M. Sage, eds., Oxford Handbook of U.S. Health Law (Oxford: Oxford University Press, 2017): 1097-1112.

3. See, e.g., World Health Organization Commission on the Social Determinants of Health, Closing the Gap in a Generation: Health Equity Through Action on the Social Determinants of Health (2008) at 1, available at <http://whqlibdoc. who.int/publications/2008/9789241563703 eng.pdf> (last visisted November 22, 2019) ("[The] unequal distribution of health-damaging experiences is not in any sense a 'natural' phenomenon but is the result of a toxic combination of poor social policies and programmes, unfair economic arrangements, and bad politics. Together, the structural determinants and conditions of daily life constitute the social determinants of health and are responsible for a major part of health inequities between and within countries.")

4. $\quad$ See Burris, supra note 2, at 1654

5. See, e.g., R.A. Epstein, "In Defense of the 'Old' Public Health," Brooklyn Law Review 69, no. 4 (2004): 1421-1470, at 1424 (" $[\mathrm{T}]$ he case for government intervention ... gets that extra boost of legitimacy" when framed as a public health issue."); P. Skrabanek, The Death of Humane Medicine and the Rise of Coercive Healthism (Suffolk: St. Edmundsbury Press, 1994): at 11 ("The roads to unfreedom are many. Signposts on one of them bear the inscription HEALTH FOR ALL."); L.F. Wiley, "Rethinking the New Public Health," Washington and Lee Law Review 69, no. 1 (2012): 207-272 (describing and refuting libertarian critiques of an expansive scope for public health law).

6. M.A. Hall, "The Scope and Limits of Public Health Law," Perspectives in Biology and Medicine 64, no. 3 (2003): S199-S209, at S199 ("explor[ing] the proper scope of public health legal authority in response to compelling scientific evidence about the social determinants of health."); Id., at S208 ("Beyond the public health arena, there are other good reasons for the government to pursue the more general aims of education, taxation, regulation, and redistribution, but these are broader social and economic policies or they belong to legal realms other than health. Public health advocates can be commended for calling our attention to the health implications of social disparities, but health promotion should not be the primary objective of corrective measures."); see also M.A. Rothstein, "The Limits of Public Health: A Response," Public Health Ethics 2, no. 1 (2009): 84-88, at 86 ("concerns about social justice should play a part in priority setting for public health. My point is simply that resolution of underlying socioeconomic and political problems is beyond the domain of public health.")

7. E. McCuskey, "The Body Politic: Federalism as Feminism in Health Reform," St. Louis University Journal of Health Law É Policy 11, no. 1 (2018): 303-316, at 310 (““(H)ealth law' has expanded from medical liability and bioethics into a diverse field encompassing regulation of all aspects of human health and the health care system.")

8. See, e.g., R.A. Williams, Jr., "Taking Rights Aggressively: The Perils and Promise of Critical Legal Theory for Peoples of 
Color," Law छ Inequality 5, no. 1 (1987): 103-134 (describing critical legal theory). Although this essay focuses specifically on feminist legal theory (including intersectional and critical race feminism), we note that critical race theory offers another set of perspectives that health law scholars have used to propose solutions to health problems and inequities. For example, Derrick Bell, a pioneer in critical race theory, asserted that "the interest of blacks in achieving racial equality will be accommodated only when it converges with the interests of whites." See D.A. Bell, Jr., "Brown v. Board of Education and the Interest-Convergence Dilemma," Harvard Law Review 93, no. 3 (1980): 518-533, at 523. This contention is the basis of interest-convergence theory and has been applied to health law issues. See D.B. Matthew, Just Medicine: A Cure for Racial Inequality in American Health Care (New York: New York University Press, 2015): at 28; see also M. Crossley, "Black Health Matters: Disparities, Community Health, and Interest Convergence," Michigan Journal of Race and Law 22, no. 1 (2016): 53-100, at 59-60.

9. There is much complexity in the term woman and how it is used. When we use the term woman throughout the article, this includes transgender men and others who may identify as a woman. See C. Strangio, "Can Reproductive Trans Bodies Exist?" City University of New York Law Review 19, no. 1 (2016): 223-245, at 230-232.

10. "The woman question asks about the gender implications of a social practice or rule: have women been left out of consideration? If so, in what way; how might that omission be corrected? What difference would it make to do so? In law, asking the woman question means examining how the law fails to consider the experiences and values that seem more typical of women than of men, for whatever reason, or how existing legal standards and concepts might disadvantage women. The question assumes that some features of the law may be not only nonneutral in a general sense, but also 'male' in a specific sense. The purpose of the woman question is to expose those features and how they operate, and to suggest how they might be corrected." K.T. Bartlett, "Feminist Legal Methods," Harvard Law Review 103, no. 4 (1990): 829-888, at 837.

11. R. West, "Introduction to Research Handbook on Feminist Jurisprudence" in R. West and C.G. Bowman, eds., Research Handbook on Feminist Jurisprudence (Northhampton, MA: Edward Elgar, 2019): at 1.

12. M.A. Fineman, "Vulnerability and Inevitable Inequality," Oslo Law Review 4, no. 3 (2017): 133-149, at 148; see also M.A. Fineman, "The Limits of Equality: Vulnerability and Inevitable Inequality," in R. West and C.G. Bowman, eds., Research Handbook on Feminist Jurisprudence (Northhampton, MA: Edward Elgar, 2019): 73-90.

13. M.O. Little, "Why a Feminist Approach to Bioethics?" Kennedy Institute of Ethics Journal 6, no. 1 (1996): 1-18, at 3 ("Under androcentrism ... we tend to anchor man as the reference point and view woman's nature as a departure from his.")

14. J. Nedelsky, Law's Relations: A Relational Theory of Self, Autonomy, and Law (Oxford: Oxford University Press, 2011): at 5 .

15. Kimberlé Crenshaw first introduced the term intersectionality to describe "how the experiences of women of color are frequently the product of intersecting patterns of racism and sexism, and how these experiences tend not to be represented within the discourses of either feminism or antiracism. Because of their intersectional identity as both women and of color within discourses that are shaped to respond to one or the other, women of color are marginalized within both." K. Crenshaw, "Mapping the Margins: Intersectionality, Identity Politics, and Violence Against Women of Color," Stanford Law Review 43, no. 6 (1991): 1241-1299, at 1243-1244.

16. See, e.g., L. Ross, "What Is Reproductive Justice?" in ProChoice Public Education Project and Sister Song Women of Color Reproductive Justice Collective, Reproductive Justice Briefing Book: A Primer on Reproductive Justice and Social Change, at 4-5, available at <https://www.protectchoice.org/
downloads/Reproductive\%20Justice\%20Briefing\%20Book. pdf $>$ (last visited November 22, 2019).

17. See, e.g., D. Dinner, "The Costs of Reproduction, History and the Legal Construction of Sex Equality," Harvard Civil RightsCivil Liberties Law Review 46 (2011): 415-495, 457 (describing feminist advocates' efforts to "redefine childrearing as a collective, public responsibility rather than a private responsibility of individual women"); R. Cohen, "Feminist Thought and Corporate Law: It's Time to Find Our Way Up from the Bottom (Line)," American University Journal of Gender and the Law 2 (1994): 1-36, at 20-22 (characterizing feminist theory as seeking "elimination of the duality of reason and emotion, public and private, political and personal," which "have been the justification for the devaluation of the traditional female domain, and the equation of power with the traditional male domain" and arguing that feminist theory "can contribute new perspectives to [debates in corporate law] by "offer[ing] a perspective that approaches the issue of responsibility from a unitary, rather than a fragmented, perspective.").

18. See D. Dinner, "Strange Bedfellows at Work: Neomaternalism in the Making of Sex Discrimination Law," Washington University Law Review 91 (2014): 453-530, 458 (describing Fineman's vulnerability analysis as "theorizing the privatization of dependency").

19. See Fineman, supra note 12.

20. W. Kissick, Medicine's Dilemmas: Infinite Needs Versus Finite Resources (New Haven: Yale University Press, 1994), at 150 (describing the iron triangle of health care: cost, quality, and access); B. Furrow et al., eds., Health Law: Cases, Materials, and Problems, 8th ed. (Saint Paul: West, 2018), at 495 (" $[\mathrm{H}]$ ealth care systems are frequently evaluated on their ability to provide equitable access to quality health care at a reasonable price for the population. In the American health care system, we also highly prioritize the ability to have choice ...?

21. For a similar argument from a British health law scholar, see K. O’Donovan, "Is the Patient Position Inevitably Female?" Foreword to Feminist Perspectives on Health Care Law, in S. Sheldon and M. Thomson, eds. (London: Cavendish Publishing Ltd., 1998): at vii (arguing that "[f] ]eminist jurisprudence can "alter[] the way in which [health care law] is researched, taught and understood" in ways that are "not confined to the 'reproductive ghetto,' that is to issues of gender and physical differences, of particular female conditions, of uteri and ovaries.").

22. K. Mutcherson, "Fetal Rights in the Trump Era," Texas Law Review 95, no. 6 (2017): 214-220, at 219 ("Abortion foes will continue to use all tools at their disposal to make it ever more difficult - and, in some cases, impossible - for women to safely end their pregnancies, resulting in the births of more children born to reluctant or unwilling mothers or more women injuring themselves through attempts to self-induce abortions.")

23. E. Chemerinsky and M. Goodwin, "Abortion: A Woman's Private Choice," Texas Law Review 95, no. 6 (2017): 1189-1247, at 1245 ("Many states have adopted various types of laws requiring that women be informed of the characteristics of the fetus at the time of abortion."); M. Manian, "Irrational Woman: Informed Consent and Abortion Regret," Duke Journal of Gender Law and Policy 16, no. 2 (2009): 223-292, at 226 (noting the Supreme Court's culmination of "[a] growing disrespect for women's decision-making capabilities...").

24. E. Kukura, "Obstetric Violence," Georgetown Law Review 106, no. 3 (2018): 721-801.

25. See N. Sawicki, "The Abortion Informed Consent Debate: More Light, Less Heat," Cornell Journal of Law and Public Policy 21, no. 1 (2011): 1-38, at 37 ("A nuanced view of informed consent doctrine will be helpful in resolving the heated debate surrounding abortion disclosure statutes."); see also B.J. Hill, "Reproductive Rights as Health Care Rights," Columbia Journal of Gender and Law 18, no. 2 (2009): 501549 , at 502-503 ("If abortion is placed in the framework of health care, the right to access abortion may then be con- 
sidered to be an aspect of the right to health. This right to health, moreover, should be conceived as a negative right, not as a positive right ... A negative right to health could ... be understood as a right against government interference in health care access and medical decision making, rather than a right to government-provided medical services.); see also Y. Lindgren, "The Rhetoric of Choice: Restoring Healthcare to the Abortion Right," Hastings Law Journal 64, no. 5 (2013): 385-422, at 391-392 ("Reclaiming abortion as a right of both healthcare and choice offers the potential for reclaiming the right within the larger framework of reproductive justice by granting all pregnant women, women who carry to term as well as women who choose to terminate their pregnancies, the right to exercise bodily autonomy and access healthcare in every aspect of their reproductive lives.")

26. See Ross, supra note 16, at 4-5.

27. J. Nedelsky, Law's Relations: A Relational Theory of Self, Autonomy, and Law (Oxford: Oxford University Press, 2011): at 5; C. Mackenzie and N. Stoljar, eds., Relational Autonomy: Feminist Perspectives on Autonomy, Agency, and the Social Self (New York: Oxford University Press, 2000): at 5; J. Llewellyn and J. Downie, eds., in Being Relational: Reflections on Relational Theory and Health Law (Seattle: University of Washington Press, 2011): at 4. ("We can see the ways in which being in relationship is integral to self-understanding and to interactions with others at individual, collective, and even institutional levels.")

28. See Nedelsky, supra note 14 , at 5 ("Generally, the rights the relational self is entitled to will need to be relational rather than individualistic conceptions. Both law and rights will then be understood in terms of the relations they structure-and how those relations can structure core values, such as autonomy.")

29. J. Nedelsky, "Reconceiving Autonomy: Sources, Thoughts, and Possibilities," Yale Journal Law and Feminism 1, no. 1 (1989): 7-36.

30. Y. Braudo-Bahat, "Towards A Relational Conceptualization of the Right to Personal Autonomy," American University Journal of Gender, Society Policy, and Law 25, no. 2 (2017): 111-154, at 129-130 ("Contrary to the liberal, individualistic conception of autonomy, the relational conception highlights the relational nature of persons, and the development of their identity and autonomy through social connections and relationships with others. Being a part of relationships and social networks makes all persons interdependent; however, interdependence does not infringe their autonomy, but is rather simply an inherent part of their personhood.")

31. P. Laufer-Ukeles, "Reproductive Choices and Informed Consent: Fetal Interests, Women's Identity, and Relational Autonomy," American Journal Law \& Medicine 37, no. 4 (2011): 567-623, at 568-569 ("Based on the uniquely intertwined relationship between women and fetuses during gestation, and the importance of reproduction to women's identity, the individualistic, narrow informed consent doctrine is unsuited to support women's autonomy in the context of reproductive choices.")

32. $I d$. , at 573 .

33. Id., at 571 ("Based on the uniquely intertwined relationship between women and fetuses during gestation, and the importance of reproduction to women's identity, the individualistic, narrow informed consent doctrine is unsuited to support women's autonomy in the context of reproductive choices.")

34. See S.M. Suter, "The 'Repugnance' Lens of Gonzales v. Carhart and Other Theories of Reproductive Rights: Evaluating Advanced Reproductive Technologies," George Washington Law Review 76, no. 6 (2008): 1514-1598, at 1593 (“... a richer notion of self-definition (and the autonomy or decisional privacy interests that derive from this conception) requires us to think of the self in relation to family, friends, and community."); see also S. Mohapatra, "Using Egg Freezing to Extend the Biological Clock: Fertility Insurance or False Hope?" Harvard Law and Policy Reviere, 8, no. 2 (2014): 381-411, at 409 ("When a woman chooses to freeze her eggs, the choice may not be truly autonomous if she is doing it because of constraints she faces at work, with family life, or with childcare. If having a child earlier means that she will take a step back in her career or not have enough money for child care due to a lack of support at home and lack of affordable child care options, then a woman may not be exercising autonomy by delaying motherhood. Instead, she may feel like this is choosing the best of many bad options.")

35. J. Llewellyn, "A Healthy Conception of Rights? Thinking Relationally about Rights in a Health Care Context," in J. Downie and E. Gibson, eds., Health Law At The Supreme Court of Canada (Toronto: Irwin Law Inc., 2007): at 57.

36. M.S. Wright, "End of Life and Autonomy: The Case for Relational Nudges in End-of-Life Decision-Making Law and Policy," Maryland Law Review 77, no. 4 (2018): 1061-1141, at 1093-1094 "Coupled with the reality that most people never make decisions without the participation of others, feminist philosophers, bioethicists, and critical disability scholars have thus advanced the concept of "relational autonomy." Importantly, relational autonomy is autonomy, just conceptualized in a way that accords with social reality.") Internal quotations omitted; L.H. Igel and B.H. Lerner, "Moving Past Individual and 'Pure' Autonomy: The Rise of Family-Centered Patient Care," American Medical Association Journal of Ethics 18, no.1 (2016): 56-62, at 58; A. Ho, "Relational Autonomy or Undue Pressure? Family's Role in Medical Decision-Making," Scandinavian Journal of Caring Sciences 22, no. 1 (2008): 128135 , at 131 (“... our self is constituted to an important degree by relations with and responsibilities towards our intimates, and these relations and the welfare of our loved ones may be more significant than the interests of any individual self in isolation.")

37. J. Downie and J. Lllewellyn, "Relational Theory and Health Law and Policy," Health Law Journal 193, Special Edition (2008): 193-210, at 197

38. Id., at 198 .

39. See Wright, supra note 36 , at 1139

40. J. Mantel, "An Unintended Consequence of Payment Reforms: Providers Avoiding Nonadherent Patients," Journal of Law, Medicine छ Ethics 46, no. 4 (2018): 931-934, at 933 ("Nonadherent patients, with their poorer health outcomes and higher costs, threaten providers' financial success under new payment models that reward quality improvements and reduced health costs. Providers can escape this predicament by firing or otherwise refusing to treat nonadherent patients, actions permitted under current legal standards and the medical profession's ethical guidelines.")

41. M. Leonard et al., Achieving Safe and Reliable Healthcare: Strategies and Solutions (Chicago: Health Administration Press, 2004): at 3.

42. E.E. Petersen, et al., "Vital Signs: Pregnancy-Related Deaths, United States, 2011-2015, and Strategies for Prevention, 13 States, 2013-2017," Morbidity and Mortality Weekly Report 68, no. 18 (2019): 423-429.

43. K. Gallo and L. Smith, "Meeting Tomorrow's Healthcare Needs: Teamwork Trumps Autonomy," Nursing Education Perspectives 31, no. 4 (2010): 207 at 207.

44. L.C. Ikemoto, "In the Shadow of Race: Women of Color in Health Disparities Policy," University of California Davis Law Review 39, no. 3 (2006): 1023-1060, at 1055; see also, E.S. Vanderstar, "Workplace Bullying in the Healthcare Professions," Employee Rights and Employment Policy Journal 8, no. 2 (2004): 455-473, at 460 ("The medical professions can be neatly arranged in a hierarchy resembling a caste system from the most influential and powerful to the least: doctors, physician's assistants, nurse practitioners, registered nurses, licensed practical nurses, technicians, orderlies, transport staff, nurse assistants, housekeeping staff."); see also, G. Shannon et al., "Gender Equality In Science, Medicine, And Global Health: Where Are We At And Why Does It Matter?" The Lancet 393, no. 10171 (2019): 560-569, at 562 ("Approximately 
$75 \%$ of the global health workforce is female, yet women disproportionately represent lower cadres of health workers.")

45. L.G. Smith and M. Anderson, "New Directions in American Health Care," Hofstra Law Revierw 39, no. 1 (2011): 23-39 at 39 ("Many doctors have clung to the nineteenth century model of status, hierarchy, autonomy, and privilege that has served them, but not always their patients, so well for so long.") These hierarchies often are exacerbated by racial inequalities in the health care workforce and between physicians and patients. See K. M. Bridges, Reproducing Race: An Ethnography of Pregnancy as a Site of Racialization (Berkeley: University of California Press, 2011) ("There was a fascinating racially significant chain of command in the clinic: white persons, with the most power and prestige in the clinic sat at the top of the hierarchy with their non-white assistants populating the ranks below them. Furthermore the racial dynamic within the clinic made even more fascinating by the racial composition of the patients served there - the large majority were racial minorities. This was a predominantly white group of providers practicing medicine upon a largely disempowered disenfranchised, marginalized and importantly non-white group of patients.")

46. L.G. Trubek and M. Das, "Achieving Equality: Healthcare Governance in Transition," American Journal of Law छ Medicine 29, no. 2 (2003): 395-430, at 415 ("By working in a nonhierarchical fashion and deeming all members of the team to be "clinical professionals," these new teams of nurses, physician assistants, community outreach workers, quality managers and physicians create better outcomes by working together rather than individually.")

47. O. Rabinovich-Einy, "Beyond IDR: Resolving Hospital Disputes and Healing Ailing Organizations Through ITR," Saint John's Law Review 81, no. 1 (2007): 173-196, at 183.

48. E.N. Glen, "From Servitude to Service Work: Historical Continuities in the Racial Division of Paid Reproductive Labor," Signs: Journal of Women in Culture and Society 18, no. 1 (1992): 1-43, at 23.

49. J.E. Harris, "Cultural Collisions and the Limits of the Affordable Care Act," Journal of Gender Social Policy छ the Law 22, no. 2 (2014): $387-449$, at 446 .

50. H. Logghe et al., “\#ILookLikeASurgeon: Embracing Diversity to Improve Patient Outcomes," British Medical Journal 359, no. 8125 (2017): j4653, at j4653 ("Participants using this hashtag have acknowledged both the need to change the image of surgeons, and that there must be no singular image - that the appearance, motivations, and behaviours of surgeons are as varied as humanity.")

51. G. Shannon et al., "Gender Equality in Science, Medicine, and Global Health: Where Are We At And Why Does It Matter?" The Lancet, 393, no. 10171 (2019): 560-569, at 566.

52. Id., at 566 ("A study investigating mortality of female patients with acute myocardial infarction found higher mortality in women treated by male doctors than in those treated by female doctors. The effect was attenuated if male doctors had higher exposure to female patients and physician colleagues.")

53. L.C. Ikemoto, "Racial Disparities in Health Care and Cultural Competency," St. Louis University Law Journal 48, no. 3 (2003): 75-131, at 82; see also, S.A. Law, "A Consumer Perspective on Medical Malpractice, Law and Contemporary Problems," Law and Contemporary Problems 49, no. 2 (1986): 305-326, at 314 ("Doctors, nurses, and other health care workers...are divided by hierarchical organizational structures. It is difficult to develop relationships of mutual respect, sharing, and criticism between physicians who are generally white, male, and affluent, and the people, often nonwhite women, who provide most 'hands-on' patient care in the hospital.")

54. See K. Davies, "The Body and Doing Gender: The Relations between Doctors and Nurses in Hospital Work," Sociology of Health Eं Illness 25, no. 7 (2003): 720-742; C. West, "When the Doctor Is a "Lady": Power, Status and Gender in Physician-Patient Encounters," Symbolic Interaction 7, no. 1 (1984): 87-106; J. Cassell, "Doing Gender, Doing Surgery: Women Surgeons in a Man's Profession," Human Organization 56, no.
1 (1997): 47-52; N.Tabassum and A. Chiesi, "Doing and Undoing Gender in the Hospital Workplace," Journal of Interdisciplinary Feminist Thought 10, no. 1 (2017): 1-23, at 15.

55. See supra note 54 (Tabassum and Chiesi), at 10.

56. M. Crossley, "Infected Judgment: Legal Responses to Physician Bias," Villanova Law Review 48, no. 1 (2017): 195-324, at 302-303 ("Published studies suggest that bias based on a clinically irrelevant characteristic of a patient at times influences some physicians' medical judgments. These biased medical decisions can have adverse impacts on the particular patient who is the victim of the biased decision, as well as on the public's health more broadly.")

57. P.T. Hoope-Bender, et al., "Improvement of Maternal and Newborn Health through Midwifery," The Lancet 384, no. 9949 (2014): 1226-1235.

58. E. R. Declercq at al., "Serving Women in Need: Nurse-Midwifery Practice in the United States," Journal of Midwifery $\boldsymbol{\sigma}^{\circ}$ Women's Health 46, no. 1 (2011): 11-16, at 13.

59. S.H. Suarez, "Midwifery Is Not the Practice of Medicine," Yale Journal of Law छ Feminism 5, no. 2 (1992): 315-364, at 315.

60. B.N. Greenwood, S. Carnahan, and L. Wang, "Patient-Physician Gender Concordance and Increased Mortality among Female Heart Attack Patients," Proceedings of the National Academy of Science 115, no. 34 (2018): 8569-8574.

61. C. Pateman, "Feminist Critiques of the Public/Private Dichotomy," in S.I. Benn and G.F. Gaus, eds., Public and Private in Social Life 281-303, at 281 (New York: St. Martin's Press, 1983) ("The dichotomy between the private and the public is central to almost two centuries of feminist writing and political struggle; it is, ultimately, what the feminist movement is about."); R. Gavison, "Feminism and the Public/Private Distinction," Stanford Law Review 45, no. 1 (1992): 1-45.

62. R. Prokhovnik, "Public and Private Citizenship: From Gender Invisibility to Feminist Inclusiveness," Feminist Review 60, no. 3 (1998): 84-104, at 87.

63. C. Hanisch, "The Personal Is Political," in S. Firestone, ed., Notes From the Second Year: Women's Liberation (1970): at 76-78, available at <https://repository.duke.edu/dc/wlmpc/ wlmms01039> (last visited November 22, 2019); cited in R. Cohen and S. O’Byrne, "'Can You Hear me Now...Good!' Feminism(s), the Public/Private Divide, and Citizens United v. FEC," UCLA Women's Law Journal 20, no. 1 (2013): 39-70.

64. See Fineman, supra note 12.

65. D. Stone, "The Struggle for the Soul of Health Insurance," Journal of Health Politics, Policy and Law 18, no. 2 (1993): 287317 , at 289 (contrasted the principle of mutual aid, whereby "sickness is widely accepted as a condition that should trigger mutual aid," and the principle of actuarial fairness, which holds that "each person should pay for his own risk."); A. Gluck and N. Huberfeld, "What Is Federalism in Health Care For?” Stanford Law Review 70, no. 6 (2018): 1689-1803, at 1698 (although the ACA "pushed the needle toward solidarity by enacting policies aimed at universal coverage," health law "remains caught in centuries-old, unresolved tension between the so-called 'social solidarity' model ... and the 'individual responsibility' model.”); E. McCuskey, supra note 7, at 310 ("Health reform movements of late suffer from that tension, but tilt definitively toward social solidarity and recognition of social determinants.")

66. See McCuskey, supra note 7 , at 315 .

67. S.L. Waysdorf, "Fighting for Their Lives: Women, Poverty, and the Historical Role of United States Law in Shaping Access to Women's Health Care," Kentucky Law Journal 84, no. 4 (1996): 745-826.

68. See, e.g., N. Huberfeld and J.L. Roberts, "Health Care and the Myth of Self-Reliance," Boston College Law Review 57, no. 1 (2016): 1-60, at 3 ("The ACA reversed [the] norm [of exclusion in health care], espousing a principle of inclusion or "universality" by facilitating universal health insurance coverage."); cf. G.R. Majette, "Global Health Law Norms and the PPACA Framework to Eliminate Health Disparities," Howard Law Journal 55, no. 3 (2012): 887-936, at 892. (“[The ACA] 
constitutes framework legislation that complies with global health law norms protecting a right to health in its approach to the reduction of health care disparities for racial and ethnic minorities in the United States.")

69. See McCuskey, supra note 7, at 314 .

70. G. Franke-Ruta, "Why Is Maternity Care Such an Issue for Obamacare Opponents?” The Atlantic, November 22, 2013, available at <https://www.theatlantic.com/politics/ archive/2013/11/why-is-maternity-care-such-an-issue-forobamacare-opponents/281396/> (last visited November 22, 2019).

71. See, e.g., V.L. MacDougall, "Medical Gender Bias and Managed Care," Oklahoma City University Law Review 27, no. 3 (2002): 781-910; T. F. Theodos, "The Patient's Bill of Rights: Women's Rights Under Managed Care and ERISA Preemption," American Journal of Law छீ Medicine 26, no. 1 (2000): 89-108; M. Oberman and M. Schaps, "Women's Health and Managed Care," Tennessee Law Review 65, no. 2 (1998): 555-583.

72. See MacDougall, supra note 71.

73. See, e.g., M.A. Fineman, "The Vulnerable Subject and the Responsive State," Emory Law Journal 60, no. 2 (2010): 251275, at 266; M.A. Fineman, "The Vulnerable Subject: Anchoring Equality in the Human Condition," Yale Journal of Law E Feminism 20, no. 1 (2008): 1-23.

74. A. Ahmed, "'Rugged Vaginas' and 'Vulnerable Rectums': The Sexual Identity, Epidemiology, and Law of the Global HIV Epidemic," Columbia Journal of Gender and Law 26, no. 1 (2013): 1-57, at 49 ("Martha Fineman argues that instead of an identity-based legal reform project we should instead focus on the construction of a new liberal subject based on an appreciation of the human condition in order to effectively displace the rhetoric of personal responsibility, small government, and condemnation of state intervention.")

75. N.A. Kohn, "Vulnerability Theory and the Role of Government," Yale Journal of Law Eீ Feminism 26, no. 1 (2014): 1-27, at 13 (critiquing the application of vulnerability theory in elder care but noting that "vulnerability theory helps us understand why we might favor laws that provide broad-based social support and why we might be concerned about selectively allocating resources based on group identity.")

76. See S.M. Stephens, "Freedom from Religion: A Vulnerability Theory Approach to Restricting Conscience Exemptions in Reproductive Healthcare," Yale Journal of Law E Feminism 29, no. 1 (2017): 93-121, at 106 (" [T] he healthcare industry is not regulated in a way that ensures access to healthcare resources that will improve human resiliency. To the contrary, the state of the law actually discourages access to critical reproductive care that can improve not only individual health outcomes but broader social and economic outcomes for patients, their families, and, in turn, their wider communities.")

77. M.A. Fineman, "Vulnerability and Inevitable Inequality," Oslo Law Review 4, no. 3 (2017): 133-149; see also, Fineman, supra note 11.

78. Id.

79. See Huberfeld and Roberts, supra note 68, at 1.

80. M.B. Lawrence, "Against the Safety Net," Florida Law Review 72, no. 1 (forthcoming 2020).

81. A. K. Hoffman, "Reimagining the Risk of Long-Term Care," Yale Journal of Health Policy, Law छ Ethics 16, no. 2 (2016): 239-315.

82. See, e.g., M. Bobinski, "Women and HIV: A Gender-Based Analysis of a Disease and its Legal Regulation," Texas Journal of Women and the Law 3, no. 1 (1994): 7-56; A. Ahmed, "Feminism, Power, and Sex Work in the Context of HIV/AIDS: Consequences for Women's Health," Harvard Journal of Law छ Gender 34, no. 1 (2011): 225-258.

83. See, e.g., K.H. Koo and S. Maguen, "Military Sexual Trauma and Mental Health Diagnoses in Female Veterans Returning from Afghanistan and Iraq: Barriers and Facilitators to Veterans Affairs Care," Hastings Women's Law Journal 25, no. 1 (2014): 27-38.
84. See, e.g., K.D. Arnold, "The Right to Live: A Constitutional Argument for Mandatory Preventative Health Care for Female Prisoners," William and Mary Journal of Women and the Law 10, no. 2 (2004): 343-366; K. Weatherhead, "Cruel But Not Unusual Punishment: The Failure to Provide Adequate Medical Treatment to Female Prisoners in the United States," Health Matrix: Journal of Law-Medicine 13, no. 2 (2003): 429-472; C. Chandler, "Death and Dying in America: The Prison Industrial Complex's Impact on Women's Health," Berkeley Women's Law Journal 18, no. 1 (2003): 40-60.

85. M.D. Makhlouf, "Health Justice for Immigrants," University of Pennsylvania Journal of Law and Public Affairs 4, no. 2 (2019): 235-311.

86. See, e.g., N. Daniels, "Treatment and Prevention: What Do We Owe Each Other?" in Prevention vs. Treatment: What's the Right Balance? (Oxford: Oxford Univ. Press, 2011): 176193, at 176 ("I ... argue that we have a robust social obligation to protect and promote health and that this obligation means we owe each other a reasonable array of both preventive and curative interventions.")

87. R. Rebouché, "Reproducing Rights: The Intersection of Reproductive Justice and Human Rights," University of California Irvine Law Review 7, no. 3 (2017): 579-610, at 593; V. Blake, "It's an ART not a Science: State-Mandated Insurance Coverage of Assisted Reproductive Technologies and Legal Implications for Gay and Unmarried Persons," Minnesota Journal of Law, Science, and Technology 12, no. 2 (2011): 651-713, at 678; S. Mohapatra, "Politically Correct Eugenics," Florida International University Law Review 12, no. 1 (2016): 51-80 (applying a reproductive justice lens to issues related to reproductive technologies such as CRISPR and suggesting cost and access to such technologies may exacerbate disparities); S. Mohapatra, "Fertility Preservation for Medical Reasons and Reproductive Justice," Harvard Journal of Racial and Ethnic Justice 30 (2014): 601-633 (applying a reproductive justice lens to fertility preservation for cancer patients and arguing for the necessity for insurance coverage for such patients).

88. S.A. Tovino, "Scientific Understandings of Postpartum Illness: Improving Health Law and Policy?" Harvard Journal of Law E Gender 33, no. 1 (2010): 99-173.

89. See, e.g., K. Faloon and P.M. Rosoff, "Who Pays? Mandated Insurance Coverage for Assisted Reproductive Technology," American Medical Association Journal of Ethics 16, no. 1 (2014): 63-69 (surveying existing literature debating whether infertility treatments should be financed collectively through private insurance mandates and public programs).

90. See Daniels, supra note 86 , at 176 .

91. Id., at 177 .

92. See L. Wiley, "The Struggle for the Soul of Public Health," Journal of Health Politics, Policy, छ઼ Law 41, no. 6 (2016): 11471160 , at 1149 ("The powerful resonance of "personal responsibility" indicates deep-seeded antagonism to understanding health as socially determined, to acting collectively in response to health threats, and to communitarian rationales for doing so. When health is viewed primarily as an individual, personal matter, the realm that is properly designated for 'public' concern is naturally understood to be narrowly defined.")

93. See, e.g., I.T. Winkler and V. Roaf, "Taking the Bloody Linen Out of the Closet: Menstrual Hygiene as a Priority for Achieving Gender Equality," Cardozo Journal of Law छ Gender 21, no. 1 (2014): 1-37.

94. Cf. T.M. Pope, "The Slow Transition of U.S. Law Toward a Greater Emphasis on Prevention," in H.S. Faust and P.T. Menzel, eds., Prevention vs. Treatment: What's the Right Balance? (Oxford: Oxford University Press, 2011): 219-244.

95. Wiley, supra note 92.

96. Cf. W.A. Rogers, "Feminism and Public Health Ethics," Journal of Medical Ethics 32, no. 6 (2006): 351-354, at 351 ("[Some public health activities raise] significant questions about autonomy, paternalism, and the regulation of bodies with potentially 'dangerous' features (breasts, cervixes, pregnant uteruses, adipose tissue) ... [M]any of the preventive 
aspects of public health[, which are subject to paternalistic intervention] - for example, diet, personal hygiene, or childhood exercise - are activities that are traditionally mediated through the actions of women as family carers and custodians of health and wellbeing."); W.E. Parmet, "Beyond Privacy: A Population Approach to Reproductive Rights," in J.G. Culhane, ed., Reconsidering Law and Policy Debates: A Public Health Perspective (Cambridge: Cambridge U. Press, 2010): at 15-39 (exploring how each side in the reproductive rights debate has employed public health arguments and the impact of those arguments on the courts' recognition of reproductive rights); S. Burris, "Law and the Social Risk of Health Care: Lessons from HIV Testing," Albany Law Review 61, no. 3 (1997): 831-896, at 835-836 (arguing for the application of existing disability, privacy, confidentiality, and informed consent laws - as well as the adoption of new legal frameworks specific to HIV/AIDS - "to protect people with HIV from discrimination ... and ... [to] protect medical privacy and limit HIV testing in the absence of informed consent.").
97. See Rogers, supra note 89, at 351 ("A feminist approach to health inequities leads us to examine the connections between disadvantage and health, and the distribution of power in the process of public health, using gender as an analytic category.")

98. See, e.g., C. M. Flood and A. Gross, eds., The Right to Health at the Public/Private Divide: A Global Comparative Study (Cambridge: Cambridge Univ. Press, 2014): at 1 ("Does a right to health care serve to advance greater equity or does it in fact advance the opposite result? Does the recognition of a right to health care help sustain public values (like equality) in systems that are undergoing privatization? Or, to the contrary, does a focus on rights-based norms foster individualism and exacerbate inequalities brought about by privatization? ... How do courts balance the rights of an individual against collective needs in the distribution of health care?")

99. See Williams, supra note 8, at 129-130.

100. See West, supra note 11, at 1.

101. Id. 
Copyright of Journal of Law, Medicine \& Ethics is the property of Sage Publications Inc. and its content may not be copied or emailed to multiple sites or posted to a listserv without the copyright holder's express written permission. However, users may print, download, or email articles for individual use. 